\title{
Histological and Biochemical Evaluation of the Kidney following Chronic Consumption of Hibiscus sabdariffa
}

\author{
U. U. Ukoha, S. I. Mbagwu, G. U. Ndukwe, and C. Obiagboso \\ Department of Anatomy, Faculty of Basic Medical Sciences, Nnamdi Azikiwe University, Okofia Nnewi Campus, \\ Anambra State, Nigeria
}

Correspondence should be addressed to S. I. Mbagwu; si.mbagwu@unizik.edu.ng

Received 31 August 2015; Revised 2 October 2015; Accepted 7 October 2015

Academic Editor: Antimo Di Maro

Copyright (C) 2015 U. U. Ukoha et al. This is an open access article distributed under the Creative Commons Attribution License, which permits unrestricted use, distribution, and reproduction in any medium, provided the original work is properly cited.

Hibiscus sabdariffa L. has been used traditionally as herbal medicine and has been documented to have a broad range of therapeutic effects. The present study aimed to investigate the effects of chronic administration of aqueous extract of flowers of Hibiscus sabdariffa on the histology of the kidney and some biochemical indices of renal function in male Wistar rats. Twenty (20) Wistar rats were randomly divided into four (4) groups of five rats each. The extract was administered orally in doses 200,500 , and $800 \mathrm{mg} / \mathrm{kg}$ body weight for 21 days. The kidney was harvested and processed histologically and blood samples were taken for biochemical assays. The histological results showed dose dependent pathological states and the biochemical analysis revealed a dose dependant variation in renal indices. These results suggest that chronic administration of aqueous extract of Hibiscus sabdariffa may be toxic to the kidney.

\section{Introduction}

Hibiscus sabdariffa (HS) (Linn) (family Malvaceae) is an annual dicotyledonous herbaceous shrub well known in Asia and African countries including Nigeria. Some of the components found in Hibiscus sabdariffa which accounts for its medicinal properties include anthocyanins, flavonoids, and protocatechuic acid (PCA) [1]. The nutritional composition of HS consists of protein, fat, carbohydrates, b-carotene, vitamin C, riboflavin, fibre, calcium, iron as well as phosphorus, and thiamine [2].

Some studies reported effects of HS to include reduction in blood pressure [3] and lipid peroxidation [4], hepatoprotective effects in a range of models based on toxin-induced hepatitis [5, 6], antilithiatic effect [7], anti-anaemic effect [8].

In Nigeria, a sweetened aqueous extract of HS (commonly known as zobo drink) is gradually gaining ground in the marketplace as preferred substitute for carbonated drinks as well as medicinal purposes without consideration of the body's physiological state [3].

Scientific evidences have demonstrated the nutritional and medicinal properties of HS, yet there is no guaranteed safety on its use. This is because reports on investigations carried out on medicinal plants show that they could cause damage to vital organs of the body even when considered safe for consumption [9].

In the present study, we investigated the effects of chronic administration of aqueous extract of HS on the histology of the kidney and some biochemical indices of renal function.

\section{Materials and Methods}

2.1. Preparation of Hibiscus sabdariffa Aqueous Extract. Dried samples of Hibiscus sabdariffa calyx were obtained from a popular market in Nnewi, Anambra State, Nigeria. The plant was identified and authenticated in the Department of Botany, Nnamdi Azikiwe University, Awka, Nigeria, where voucher specimen was deposited.

Aqueous extract of the plant was prepared according to the method of Iyare and Adegoke [10]. Two hundred grams (200 g) of dried Hibiscus sabdariffa calyx was boiled in $1000 \mathrm{~mL}$ of distilled water for $15 \mathrm{~min}$. The boiled sample was allowed to cool and then filtered. The filtrate was evaporated to dry in an oven at $40^{\circ} \mathrm{C}$ to produce a dark red residue. 


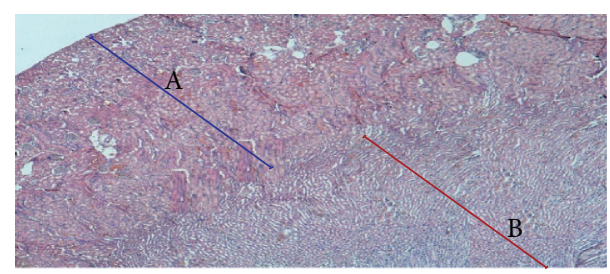

(a)

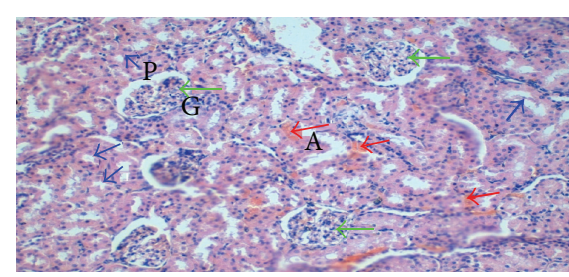

(b)

FIgURE 1: (a) Photomicrograph of the kidney sections of the control groups (fed only water and rat chow). Blue line marked A shows the renal cortex and red line marked B shows the renal medulla, with both showing normal histologic features of the kidney $(\times 100)(\mathrm{H} \& \mathrm{E})$. (b) Photomicrograph of the kidney sections of the control group. Blue arrows marked P show normal proximal tubules. Red arrows marked A show arterioles. Green arrows marked $\mathrm{G}$ indicate the glomeruli $(\mathrm{H} \& \mathrm{E} ; \times 100)$.

2.2. Experimental Animals. Healthy male Wistar rats (100$200 \mathrm{~g}$ ) used in the study were obtained from the Animal House of the Department of Zoology, Nnamdi Azikiwe University, Awka, Nigeria. They were kept in rat cages and maintained under standard laboratory conditions. The animals were acclimatized for two weeks, fed on rat pellets (Vital Feeds PLC, Nnewi, Anambra State, Nigeria), and allowed free access to clean water ad libitum. The study was approved by the Animal Welfare and Ethics Committee of Nnamdi Azikiwe University, Nnewi Campus, Nigeria. All conditions of animal use Were adhered to as obtained from United States National Institute of Health (NIH) Guide for Care and Use of Laboratory Animals. The animals were grouped into four designated as groups I-IV. Group I served as the control that received distilled water $(5 \mathrm{~mL} / \mathrm{kg})$. Groups II, III, and IV were given 200,500 , and $800 \mathrm{mg} / \mathrm{kg}$ body weight of the extract, respectively. The animals were treated orally once a day for 21 days. Twenty-four hours after the last administration, the rats were sacrificed by cervical dislocation; the abdomen was carefully dissected and the kidney was excised processed using routine histological techniques (Figure 1).

2.3. Biochemical Analysis. Before the rats were sacrificed, blood was collected from the abdominal aorta for serum assay. The concentrations of creatinine, urea, and electrolytes were determined in the serum following standard procedures as described in the respective assay kits.

2.4. Statistical Analysis. All values were expressed as mean \pm SEM. Differences between groups were evaluated by oneway ANOVA followed by Tukey multiple comparison tests. Results were considered significant at $P<0.05$.

\section{Results}

3.1. General and Physical Observation. All animals showed normal appearance and appetite. However increased water intake was observed in hand with increase in the dosage of extract administration across the groups. Increased urinary and fecal output were observed in group IV animals administered $800 \mathrm{mg} / \mathrm{kg}$ of the extract in comparison to other groups. At the end of the experiment, seemingly dose dependent

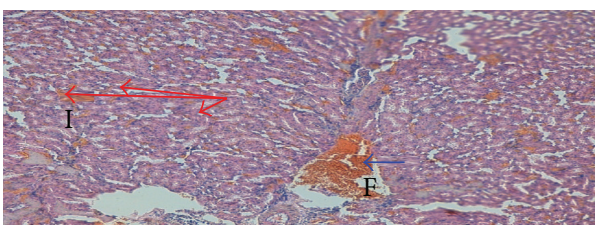

FIGURE 2: Photomicrograph of kidney sections of test group II. Red arrows marked I show mild interstitial congestion. Blue arrow marked $\mathrm{F}$ indicates focal interstitial hemorrhage which indicates mild tissue damage $(\mathrm{H} \& \mathrm{E} ; \times 100)$.

significant increases in body weight were also observed in the experimental animals.

3.2. Histological Results. The results of the histological analysis revealed that the animals in the control group showed normal histological features compared to mild interstitial congestion and focal interstitial hemorrhage observed in group II (Figure 2).

In group III congested blood vessels, focal glomerular hemorrhage and collecting tubules containing light yellow to golden-yellow pigmentation were observed (Figures 3(a), 3(b), and 3(c)).

A marked interstitial congestion, focal interstitial hemorrhage, and focal segmental glomeruli hemorrhage were observed in group IV (Figure 4).

3.3. Kidney Function Indices. Administration of aqueous extract of Hibiscus sabdariffa for 28 days with 200, 500, and $800 \mathrm{mg} / \mathrm{kg}$ body weight showed significant change in the serum levels of sodium, potassium, bicarbonate, and chloride ions as well as urea and creatinine concentrations compared with the control (Table 1).

\section{Discussion}

The kidney's functional integrity is to maintain total body homeostasis through its role in the excretion of metabolic wastes and in regulation of intracellular fluid volume, electrolyte composition, and acid-base balance [11]. This therefore implies that any harmful effect on body metabolism could be suggestive of toxic insult to the kidney [12]. 
TABLE 1: Kidney function indices of oral administration of aqueous extracts of $H$. sabdariffa in male albino rats.

\begin{tabular}{lcccccc}
\hline \multirow{2}{*}{ Group } & \multicolumn{4}{c}{ Parameters (mean \pm standard deviation) } \\
& Urea $(\mathrm{mg} / \mathrm{dL})$ & Creatinine $(\mathrm{mg} / \mathrm{dL})$ & $\mathrm{Na}^{+}(\mathrm{mmol} / \mathrm{L})$ & $\mathrm{K}^{+}(\mathrm{mmol} / \mathrm{L})$ & $\mathrm{Cl}^{-}\left(\mathrm{mmol}^{\prime} \mathrm{L}\right)$ & $\mathrm{HCO}_{3}^{-}(\mathrm{mmol} / \mathrm{L})$ \\
\hline Group A (control) & $2.8 \pm 0.10$ & $40.0 \pm 1.00$ & $145 \pm 1.00$ & $6.8 \pm 0.00$ & $102 \pm 1.00$ & $20.0 \pm 1.00$ \\
Group B (test I) & $3.0 \pm 0.10^{*}$ & $50.0 \pm 0.50^{*}$ & $150 \pm 1.00^{*}$ & $6.5 \pm 0.10^{*}$ & $109 \pm 1.00^{*}$ & $21.0 \pm 1.00$ \\
Group C (test II) & $3.1 \pm 0.10^{*}$ & $55.0 \pm 1.00^{*}$ & $145 \pm 2.00$ & $6.6 \pm 0.10^{*}$ & $110 \pm 1.00^{*}$ & $23.0 \pm 1.00^{*}$ \\
Group D (test III) & $3.7 \pm 0.10^{*}$ & $53.0 \pm 1.00^{*}$ & $150 \pm 1.00^{*}$ & $6.7 \pm 0.10$ & $108 \pm 1.00^{*}$ & $26 \pm 1.00^{*}$ \\
\hline
\end{tabular}

${ }^{*} P<0.05$.

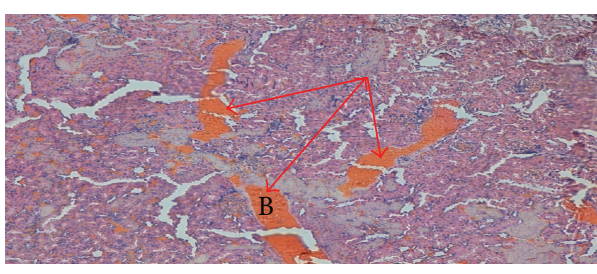

(a)

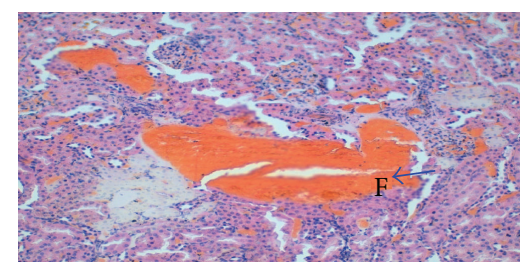

(b)

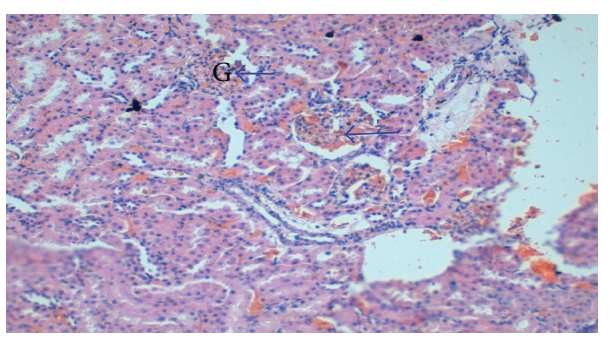

(c)

Figure 3: (a) Photomicrograph of kidney section of test group III. B shows congested blood vessels. Section shows focal interstitial hemorrhage. There are focal areas showing collecting tubules containing light yellow to golden-yellow pigmentation (H\&E; $\times 100)$. (b) Photomicrograph of kidney section of test group III. F shows focal interstitial hemorrhage (H\&E; $\times 100)$. (c) Photomicrograph of kidney section of test group III. G indicates glomerular hemorrhage $(\mathrm{H} \& \mathrm{E} ; \times 100)$.

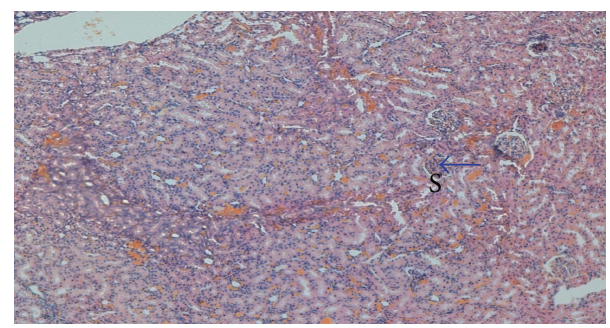

Figure 4: Photomicrograph of the kidney section of test group IV. Section shows marked interstitial congestion, focal interstitial hemorrhage, and also focal segmental glomeruli hemorrhage (H\&E; $\times 100)$.

The results from our study indicate that aqueous extract of Hibiscus sabdariffa Linn popularly known as "zobo" drink in our community has adverse effects on the body weight of the experimental animals. This is in contrast to the study by Ochani and D'mello [13], in which significant increase in the body weights of the experimental animals was observed in a pattern suggesting the influence of the administered dosage. This observation therefore questions the reported positive effect of Hibiscus sabdariffa on obesity.
The histological observations of kidney sections from the experimental animals demonstrated dose dependent pathological states such as congestion of blood vessels, focal interstitial hemorrhage, and glomerular hemorrhages.

The figures illustrate that there are mild indications of renal tissue distortion suggestive of tissue damage in the test groups, whereas the histological appearance of the control group is consistent with normal histology. It can also be inferred that the activity of Hibiscus sabdariffa extract on the kidney is dose dependent considering the increase in the level of mild tissue distortion with increase in the extract administration. Focal interstitial hemorrhage was entirely absent in the sections of the control group. However, the focal interstitial hemorrhage is seen to increase across group with increase in the dosage of the administration of the extract. Glomerular hemorrhage is entirely absent in the control group and test group II and it is seen to occur mildly in test group III but worsens in test group IV. These features demonstrate an extent of renal damage which is not in concert with the results obtained from a similar study by Kolawole et al. [14].

Assessing the levels of excretory metabolites like electrolyte, urea, and creatinine can be used to evaluate renal function $[15,16]$. Creatinine is hydrolysed from creatine 
phosphate and has been reported to be a marker of renal function. Urea is a waste product of protein metabolism and can be used as a test of renal function [17]. The observed increase in urea and creatinine level shows significant change $(P<0.05)$ compared to control group. This suggests that renal function was compromised following the administration of the extract. These results agreed with the findings of Orisakwe et al. [11] and Abubakar et al. [12].

It has been reported that aqueous extract of Hibiscus sabdariffa is rich in sodium ions $\left(\mathrm{Na}^{+}\right)$, implying that its oral consumption may increase plasma sodium $\left(\mathrm{Na}^{+}\right)$levels. A mechanism for the sodium increase could be due to the action of the flavonoid content of Hibiscus sabdariffa [4].

There was a slight significant increase in sodium $\left(\mathrm{Na}^{+}\right)$ level comparable to control group. This suggests a slight effect on the sodium pump that maintains the constancy of the extracellular concentration of potassium. The increase in plasma $\mathrm{Na}^{+}$observed may have resulted from a state of water deprivation. This is in agreement with the reports of earlier workers. For example, Mojiminiyi et al. [18], Ross and Desai [19], and Iyare and Adegoke [3] in their investigation of the diuretic property of HS observed that rats that consumed HS had elevated plasma $\mathrm{Na}^{+}$. They explained that water deprivation causes hypernatremia. Adigun et al. [20] reported that aqueous extract of HS has also been shown to be rich in $\mathrm{Na}^{+}$implying that rats consuming HS may be increasing their oral $\mathrm{Na}^{+}$load and thus consequently increased plasma $\mathrm{Na}^{+}$.

The serum potassium $\left(\mathrm{K}^{+}\right)$level was decreased. This observation is in concert with studies by Abubakar et al. [12] and Emelike and Dapper [4]. The mechanism for this is not clear.

The use of serum chloride and bicarbonate ions to assess renal functions cannot be overemphasized. Therefore the significant increase in the serum chloride and bicarbonate ions following administration of aqueous extract of $H$. sabdariffa at various doses could be indicative of tubular and glomerular dysfunction. Our observation is contrary to the study by Emelike and Dapper [4].

In general, our findings do not agree with the report by Bushra Abbas [21] but are in concert with previous studies of Kirdpon et al. [22], Orisakwe et al. [11], and Abubakar et al. [12].

\section{Conclusion}

The nephrotoxic potential of $H$. sabdariffa calyx was tested in Wistar rats after oral administration. From our findings, we suggest that chronic consumption of aqueous extract of Hibiscus sabdariffa might be toxic to the kidney by causing a distortion in the integrity of the kidney cytoarchitecture and inducing remarkable increase in serum urea, creatinine, and certain electrolytes which could interfere with normal kidney function.

\section{Conflict of Interests}

The authors declare that there is no conflict of interests regarding the publication of this paper.

\section{References}

[1] A. M. L. Seca, A. M. S. Silva, A. J. D. Silvestre, J. A. S. Cavaleiro, F. M. J. Domingues, and C. Pascoal-Neto, "Phenolic constituents from the core of Kenaf (Hibiscus cannabinus)," Phytochemistry, vol. 56, no. 7, pp. 759-767, 2001.

[2] A. Ismail, E. H. K. Ikram, and H. S. M. Nazri, "Roselle (Hibiscus sabdariffa L.) seeds-nutritional composition, protein quality and health benefits," Food, vol. 2, no. 1, pp. 1-16, 2008.

[3] E. E. Lyare and O. A. Adegoke, "Gestational outcome in rats that consumed aqueous extract of Hibiscus sabdariffa during pregnancy," Pakistan Journal of Nutrition, vol. 10, no. 4, pp. 350354,2011

[4] C. U. Emelike and D. V. Dapper, "Biochemical effects of oral administration of aqueous extract of Hibiscus sabdariffa on Wistar albino rats," IOSR Journal of Dental and Medical Sciences, vol. 9, no. 1, pp. 35-39, 2013.

[5] O. Adaramoye, B. Ogungbenro, O. Anyaegbu, and M. Fafunso, "Protective effects of extracts of Vernonia amygdalina, Hibiscus sabdariffa and vitamin $\mathrm{C}$ against radiation-induced liver damage in rats," Journal of Radiation Research, vol. 49, no. 2, pp. 123131, 2008.

[6] T. O. Ajiboye, N. A. Salawu, M. T. Yakubu, A. T. Oladiji, M. A. Akanji, and J. I. Okogun, "Antioxidant and drug detoxification potentials of Hibiscus sabdariffa anthocyanin extract," Drug and Chemical Toxicology, vol. 34, no. 2, pp. 109-115, 2011.

[7] S. Woottisin, R. Z. Hossain, C. Yachantha, P. Sriboonlue, Y. Ogawa, and S. Saito, "Effects of Orthosiphon grandiflorus, hibiscus sabdariffa and Phyllanthus amarus extracts on risk factors for urinary calcium oxalate stones in rats," Journal of Urology, vol. 185, no. 1, pp. 323-328, 2011.

[8] O. S. Falade, I. O. Otemuyiwa, A. Oladipo, O. O. Oyedapo, B. A. Akinpelu, and S. R. A. Adewusi, "The chemical composition and membrane stability activity of some herbs used in local therapy for anemia," Journal of Ethnopharmacology, vol. 102, no. 1, pp. 15-22, 2005.

[9] A. Shafaei, E. Farsi, B. M. Khadeer Ahamed et al., "Evaluation of toxicological and standardization parameters and phytochemical investigation of Ficus deltoidea leaves," American Journal of Biochemistry and Molecular Biology, vol. 1, no. 3, pp. 237-243, 2011.

[10] E. E. Iyare and O. A. Adegoke, "Maternal consumption of an aqueous extract of Hibiscus sabdariffa during lactation accelerates postnatal weight and delays onset of puberty in female offspring," Nigerian Journal of Physiological Sciences, vol. 23, no. 1-2, pp. 89-94, 2008.

[11] O. E. Orisakwe, D. C. Husaini, and O. J. Afonne, "Testicular effects of sub-chronic administration of Hibiscus sabdariffa calyx aqueous extract in rats," Reproductive Toxicology, vol. 18, no. 2, pp. 295-298, 2004.

[12] M. G. Abubakar, A. Lawal, B. Suleiman, and K. Abdullahi, "Hepatorenal toxicity studies of sub-chronic administration of calyx aqueous extracts of hibiscus sabdariffa in albino rats," Bayero Journal of Pure and Applied Sciences, vol. 3, no. 1, pp. 16$19,2010$.

[13] P. C. Ochani and P. D’mello, "Antioxidant and antihyperlipidemic activity of Hibiscus sabdariffa linn. leaves and calyces extracts in rats," Indian Journal of Experimental Biology, vol. 47, no. 4, pp. 276-282, 2009. 
[14] O. T. Kolawole, M. O. Akiibinu, and M. A. Akanji, "Assessment of the effect of aqueous extract of calyx of Hibiscus sabdariffa on some biochemical indices of renal function in rats," International Journal of Pharma Sciences, vol. 4, no. 3, pp. 587-590, 2014.

[15] J. O. Adebayo, M. T. Yakubu, E. C. Egwim, V. B. Owoyele, and B. U. Enaibe, "Effect of ethanolic extract of Khaya senegalensis on some biochemical parameters of rat kidney," Journal of Ethnopharmacology, vol. 88, no. 1, pp. 69-72, 2003.

[16] M. T. Yakubu, L. S. Bilbis, M. Lawal, and M. A. Akanji, "Evaluation of selected parameters of rat liver and kidney function following repeated administration of yohimbine," Biokemistri, vol. 15, no. 2, pp. 50-56, 2003.

[17] A. D. A. Adedapo, Y. O. Osude, A. A. Adedapo et al., "Blood pressure lowering effect of Adenanthera pavonina seed extract on normotensive rats," Records of Natural Products, vol. 3, no. 2, pp. 82-89, 2009.

[18] F. B. O. Mojiminiyi, B. J. Adegunloye, Y. A. Egbeniyi, and R. U. Okolo, "An investigation of the diuretic effect of an aqueous extract of the petals of Hibiscus sabdariffa," African Journal of Medicine and Medical Sciences, vol. 2, no. 1, pp. 77-80, 2000.

[19] M. G. Ross and M. Desai, "Gestational programming: population survival effects of drought and famine during pregnancy," The American Journal of Physiology-Regulatory Integrative and Comparative Physiology, vol. 288, no. 1, pp. R25-R33, 2005.

[20] M. O. Adigun, O. D. Ogundipe, J. I. Anetor, and A. O. Odetunde, "Dose-dependent changes in some haematological parameters during short-term administration of Hibiscus sabdariffa Calyx aqueous extract (Zobo) in Wistar albino rats," African Journal of Medicine and Medical Sciences, vol. 35, no. 1, pp. 73-77, 2006.

[21] A. Bushra Abbas, "Effects of aqueous extract of Hibiscus sabdariffa L. on some biochemical indices of liver and kidney function in male albino rats," Magazin of Al-Kufa University for Biology, vol. 6, no. 2, 2014.

[22] S. Kirdpon, S. N. Nakorn, and W. Kirdpon, "Changes in urinary chemical composition in healthy volunteers after consuming roselle (Hibiscus sabdariffa Linn.) juice," Journal of the Medical Association of Thailand, vol. 77, no. 6, pp. 314-321, 1994. 

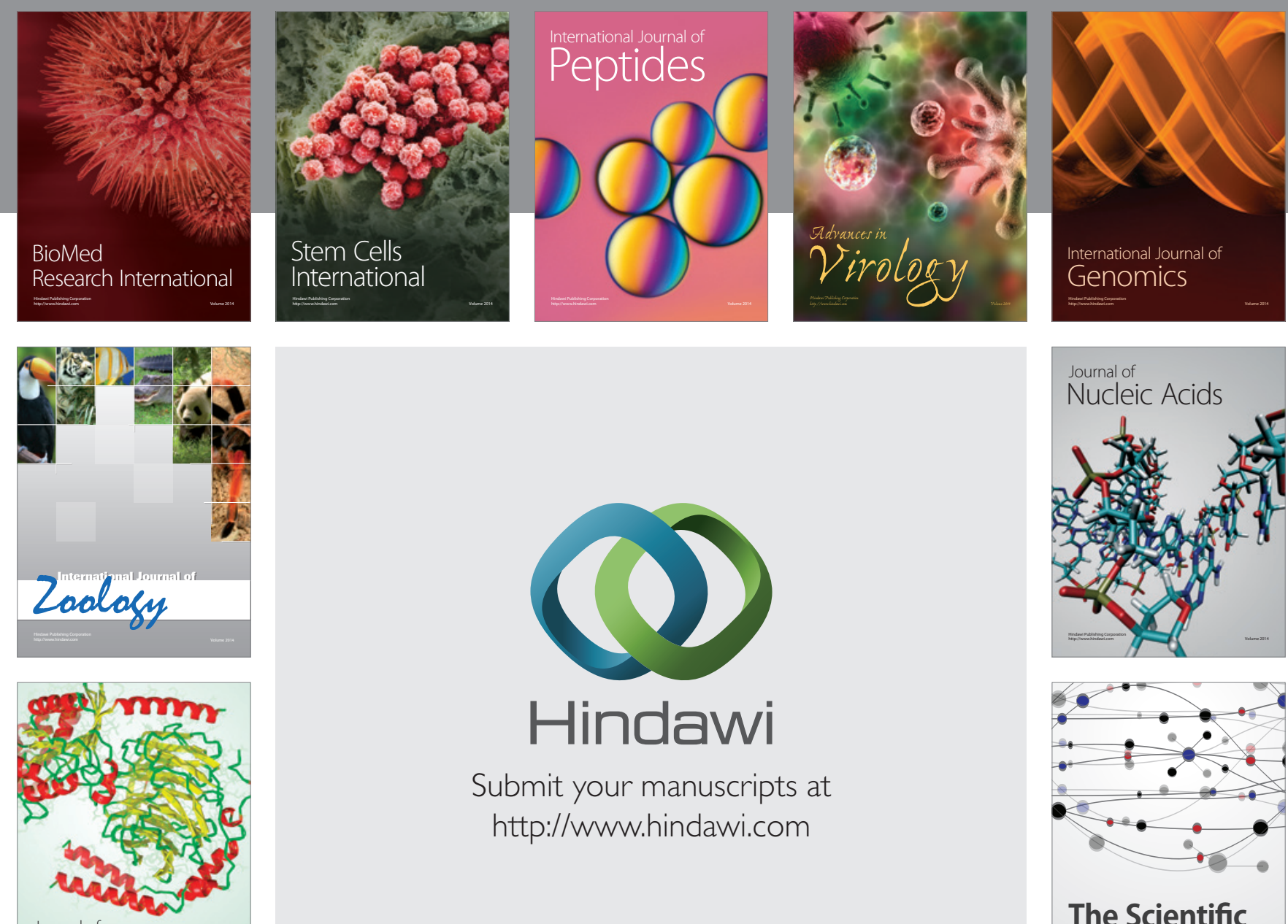

Submit your manuscripts at

http://www.hindawi.com

Journal of
Signal Transduction
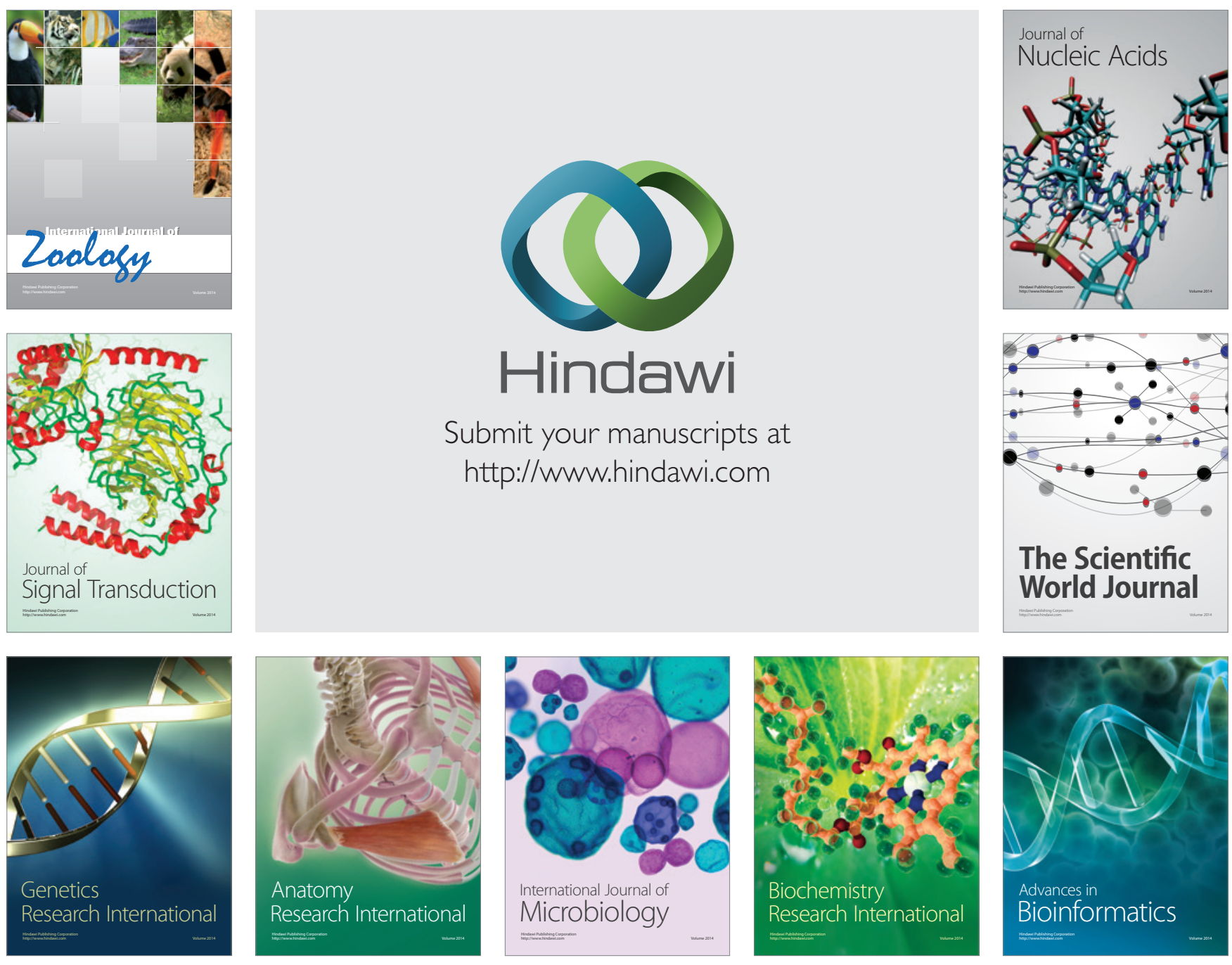

The Scientific World Journal
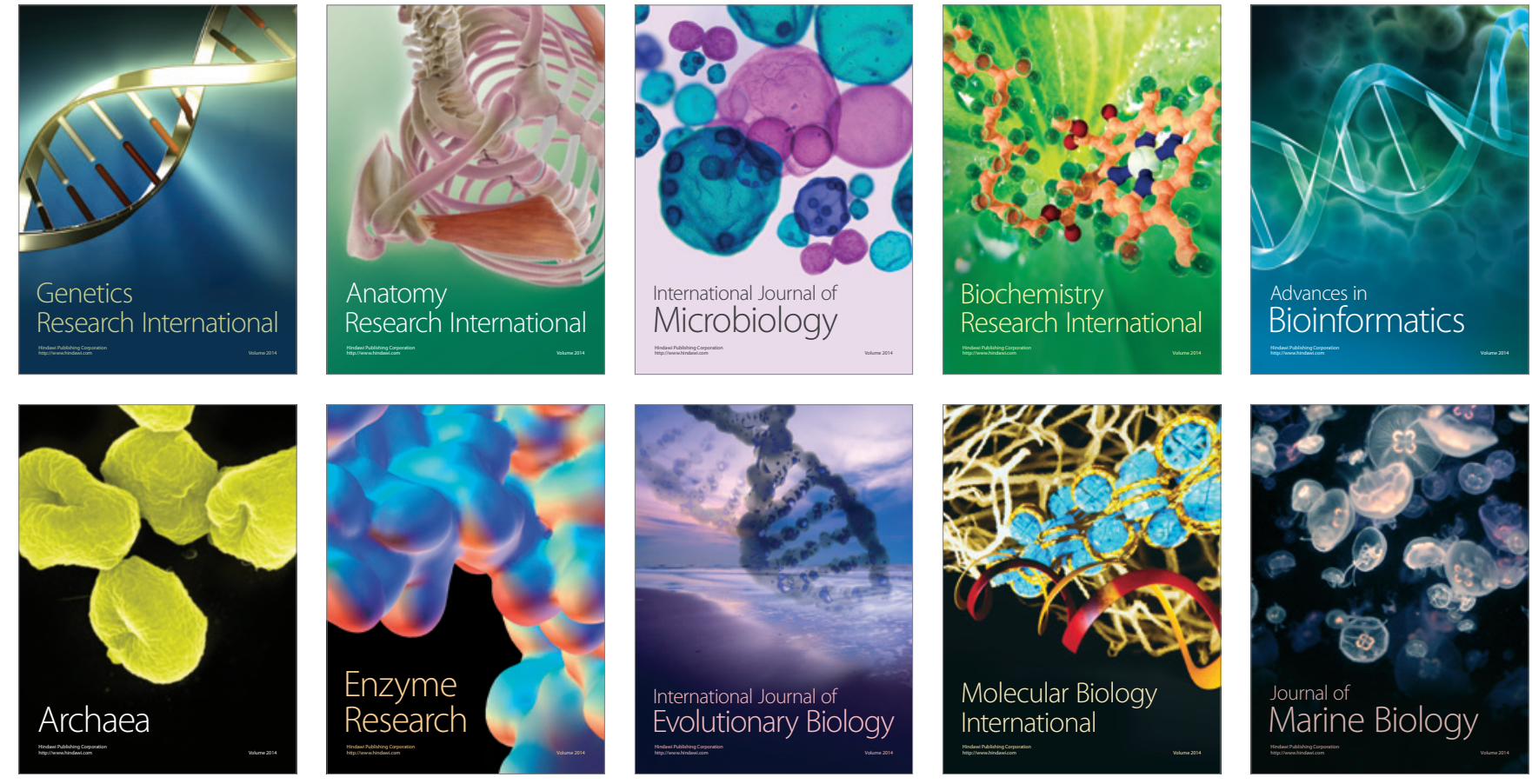